\title{
Bio-remedial Effect of Specific Micro-organisms (Bacteria) on Used Engine Oil: A Case Study of Some Mechanic Workshops in Maiduguri Metropolitan Council (MMC)
}

\author{
Yerima I., Grace A. Felix, and Munirah I. Ahmad
}

\section{ABSTRACT}

The potential of three micro-organisms (Pseudomonas, Streptococcus and Bacillus sp) were isolated from hydrocarbon contaminated soil and were evaluated for their biodegradation ability. The rate of biodegradation of the engine oil in the soil samples were exposed to used engine oil with different exposure rates of 5,10,15 and 20 years were studied for a period of three (3) weeks under greenhouse experiment. The soil samples were obtained from four different mechanic workshops in M.M.C and they were plated on nutrients agar and oil agar medium to isolate the bacterial species from the spilled soil samples All the micro-organisms used in this study showed their abilities to remediate soil exposed to used engine oil and the remediated soil samples were able to support the growth of Maize ( Zea mays) after 10 years effective growth.

Keywords: Microorganisms, Engine oil, Soil, Nutrient agar, Remediation and Maize.
Published Online: May 21, 2020

ISSN: $2684-446 \mathrm{X}$

DOI : $10.24018 /$ ejgeo.2020.1.3.11

\section{Yerima I.*}

Department of Biological Sciences University of Maiduguri, Nigeria. (e-mail: ibrahimyerima32@gmail.com)

\section{G. A. Felix}

Department of Microbiology University of Maiduguri, Nigeria. (e-mail: graceatinukefelix@gmail.com)

\section{I. Ahmad}

Department of Microbiology University of Maiduguri, Nigeria. (e-mail: munirahiahmed@gmail.com)

*Corresponding Author

\section{INTRODUCTION}

Engine oil is a thick mineral liquid applied to a machine or engine as a lubricant to reduce friction between the moving parts of the machine [3]. Viscosity is the most essential attribute of engine oil for automobile use [10]. New engine oil contains high percentage of fresh, more volatile and water-soluble hydrocarbons that would be of more concern for acute toxicity to organisms [2]. Most engine oil are produced from thicker and heavier base stock petroleum hydrocarbon obtained from crude oil with additives to develop certain attributes. Typical engine oil consists of hydrocarbons having between 18 and 34 carbon atoms per molecule. Engine oil consists of a complex mixture of hydrocarbons before it is used, this make up 80 to 90 percent of its performance and volume- 10 to 20 percent of its volume which makes up the enhancing additives [5].

Used engine oil is a lubricating oil which is removed from crankcase of internal combustion engine, as the name implies this represents oil that has undergone destructive changes in property after subjecting it to oxygen, combustion gases and high temperature. The used oil also undergoes viscosity changes as well as additive depletion and oxidation [6].

The engine oil was altered by contamination with the products of combustion and the addition of metals from the wear and tear of the engine. The major components of used engine oil consist of aliphatic and aromatic hydrocarbons such as naphthalene, phenol, benzene(a)atracene, benzo (a)pyrene, fluoranthene, lead, cadmium and other potentially toxic metals [6].

Large quantity of used engine oil from motor cars, motor bikes, generators etc are liberated into the environment. Where it is changed and disposed into gutters, water drains, open vacant plots and farmlands, a common practice by motor and generator mechanics [11].

In most countries of the world, oil spilled at automechanic workshops have been left uncared for over the years, and its continuous accumulation is of serious environmental concern because of the hazard associated with it. The physicochemical treatment technologies currently in use are expensive and not environmentally friendly. In addition, some technologies only transfer the contamination from one place to another. 
In recent times, a lot of efforts have been made towards reducing environmental pollution by using natural processes to treat environmental pollution. These techniques include; bioremediation, use of microorganisms to degrade pollutants and phytoremediation, use of plants to clean pollutants by bioaccumulation into the plant's tissues [4][8].

Bioremediation is the naturally occurring process by which microorganisms transform environmental contaminants into harmless end products in order to obtain the sources of carbon and energy. During the process of bioremediation environmental parameters such as temperature, measures of alkalinity or acidity $(\mathrm{Ph})$, oxygen and moisture content, are optimized to achieve accelerated biodegradation.

Pseudomonas which is a soil microorganism that effectively degrades xenobiotics. Different strains of pseudomonas that are capable of detoxifying more than 100 organic compound (e.g phenol, biphenyls, organophosphate, naphthalene etc.) have been identified. Some other microbial strains are also known to have the capacity to degrade xenobiotics such as Mycobacterium, Alcaligenes, Norcadia etc.

There are relatively large amount of hydrocarbons in spent engine oil including highly toxic polycyclic Aromatic Hydrocarbons (PAH). A marked change in the properties occur in soils polluted with petroleum hydrocarbons affecting the physical, chemical and microbial properties of the soil. Oil pollution leads to a buildup of essential organic nutrients such as carbon, phosphorus, calcium and magnesium and non-essential lead, zinc, iron, copper and cobalt. These elements if in excess will lead to translocation of plant tissue. Soil contaminated with engine oil that is rampant in the Nigerian environment has adverse effects for seasonal crops such as tomato (Lycopersicumesculatum) and maize (Zea mays).

This study determined the bio remedial effect of microorganisms on engine oil, with the objective of determining the effectiveness of bioremediation of soil contaminated with used engine oil, the best treatment option, which can be used to develop a safe, robust and economical treatment technology for soil contaminated with used engine oil and to identify the types of indigenous bacteria in the contaminated soil.

It is imperative to note that the increasing demand for petroleum hydrocarbons upon release through a spillage, leak or careless disposal into the environment have the potential of being washed or carried by run-offs into surface water bodies or migrating through soil particles until they reach ground water. The study of microbial removal of hydrocarbon pollutants from the soil would therefore be an essential practice in mitigating some of the environmental and health concern arising from hydrocarbon contamination of soil and water resources in Maiduguri, Borno State, Nigeria. This research therefore, seeks to investigate the removal of hydrocarbon contaminants in soil using indigenous hydrocarbon-degrading microorganisms.

The scope of bioremediation treatment is not limited to any of the technologies. Any treatment technology that has similar key features should be considered a bioremediation technology.

\section{MATERIALS AND METHOD}

\section{A. Study Area and Sample Collection}

Four (4) sampling sites were selected based on observed regular practice of vehicle metal contaminated waste oil in the vicinity of auto mobile workshops in Maiduguri Metropolitan Council, Borno State, Nigeria. Auto mobile workshops that have been in existence for more than five to twenty years were randomly selected. Surface soil samples were collected from auto mobile workshops and kept in sterile polythene bags and were transported to the laboratory of the Department of Microbiology University of Maiduguri, Borno State, Nigeria.

The samples were collected from the following locations;

$\begin{aligned} \text { i. } & \text { Lagos street } \\ \text { ii. } & \text { Polo } \\ \text { iii. } & \text { Bama motor park (Bama road) and } \\ \text { iv. } & \text { Damboa road }\end{aligned}$

The first sample of contaminated soil (sample A) was collected from Lagos street site mechanic workshop which has been in existence for 5 years, this was followed by the second soil sample (sample B) as contaminated and noncontaminant as control sample from polo which has been in existence for 10 years. The $3^{\text {rd }}$ sample (sample C) was collected along Bama motor park (Bama road), which has been in existence as auto mobile workshop for 15 years. Sample D was collected from Damboa road and the auto mobile workshop has been in existence for 20 years.

The entire procedure was followed by the following methods:

\section{B. Isolation of Microorganism}

\section{i. $\quad$ Preparation of Agar Plate}

The Agar was prepared according to the manufacturer's instruction. The solution was sterilized by autoclaving at $121^{\circ} \mathrm{C}$ for 15 minutes and subsequently cooled to about $47^{\circ} \mathrm{C}$ before use. Glass petri dishes used were also sterilized using a hot air oven at $180^{\circ} \mathrm{C}$ for an hour and half after which it was allowed to cool appreciably before use.

\section{ii. Serial Dilution}

One gram of soil sample was suspended in $9 \mathrm{mls}$ of sterile distilled water and diluted serially up to $10-10.02 \mathrm{ml}$ (aliquot) of the suspension before $1 \mathrm{ml}$ of the aliquot from each of the dilution was inoculated separately into Nutrient agar plates. The plates were incubated at $37^{\circ} \mathrm{C}$ to determine the counts after 24 hours of incubation.

\section{Preliminary Screening of Spent Engine Oil Degraders}

Isolation of bacteria from contaminated soil samples was carried out by nutrient agar pour plate technique. Pure bacterial culture was streaked on oil agar medium to determine the isolates that can utilize spent engine oil as their sole source of carbon. The oil agar medium consists of basal (mineral salts) medium which was sterile distilled water. In oil agar medium, nystatin was added to prevent the growth of fungi. Those isolates that showed good growth on oil agar medium was used for biodegradation experiment.

\section{Characterization of Bacterial Isolates}

Microscopic, biochemical and Oil spread method were used for determination of bacterial isolates and then characterized 
as described by Bergey's manual of determinative Bacteriology.

\section{i. $\quad$ Oil spread method}

To find the degraders of engine oil, 50 microliters of distilled water was dropped into a petri dish of 100 micro liters of crude oil and added to the drop of distilled water. Finally, the suspended isolates of microorganism were added to the mixture of oil with the suspension of isolated organism and water remaining undispersed looking roundish under magnifying lens.

\section{E. Green House Studies}

\section{i. $\quad$ Preparation of Seed Bags}

Each seed bag of 32 contained contaminated soil with spent engine oil prepared for this experiment, out of these, 16 seed bags contained contaminated soil samples while the other 16 seed bags contained sterilized soil samples without spent engine oil to serve as control.

\section{ii. Planting of Maize Seeds}

Two viable seeds of maize were planted in each of the seed bags. Germination of maize seeds was monitored and plant height was measured in $\mathrm{cm}$ and recorded for a period of three weeks. Watering of seed bags was carried out once daily.

\section{iii. $\quad$ Statistical Analysis}

Mean values of all the parameters taken were calculated and factorial analysis of variance (ANOVA) was also determined at 0.05 of the confidence intervals.

\section{RESUlts AND Discussion}

The responses of seed germination of maize in a contaminated soil was recorded and compared with the maize grown in non-contaminated soil (control). Different data were obtained from different location (Lagos Street, Polo, Tashan Bama and Damboa Road) and were subjected to statistical analysis using $\mathrm{T}$ test at $95 \%$ level of significance to determine the significant differences among mean of the recorded parameters.

Effect of Microorganism in Bioremediation in The Growth Responses of Maize Plant In 3 Weeks of Sowing.

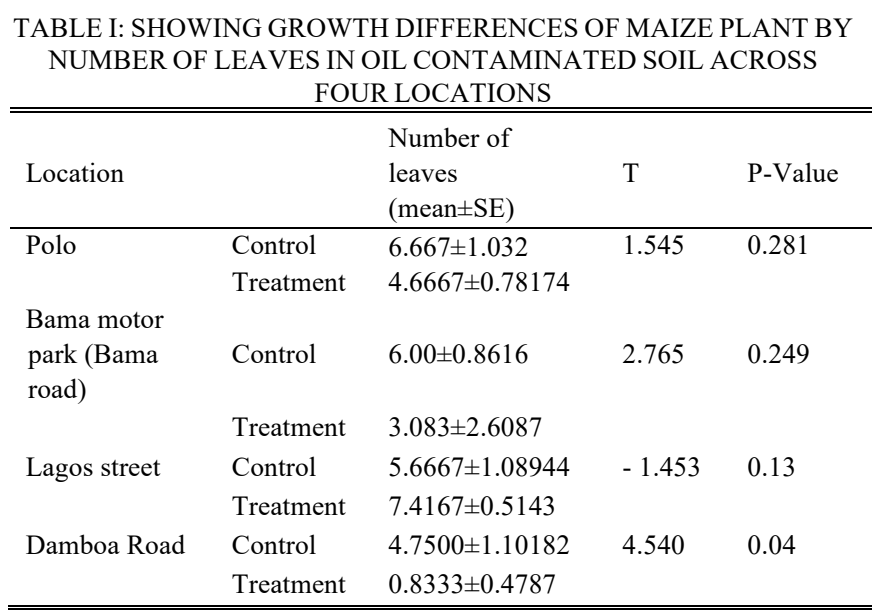

Table 1 shows the growth differences of maize plants by number of leaves in oil contaminated soil after 3 weeks of sowing. The finding reveals that maize sown in the control has the best response across the four locations. The data in
Polo, Bama motor park and Lagos Street reveals that there were no significant differences $(\mathrm{P}<0.05)$ in number of leaves between the control and the treatment. Similarly, the best response in the control was recorded in Polo showing 4.667 with least recorded in Damboa road (0.8333). The data also reveals that there was a significant difference $(\mathrm{P}<0.05)$ in number of leaves between the control and the treatment of Damboa road.

TABLE II: SHOWING GROWTH DIFFERENCES OF MAIZE PLANT BY SHOOT LENGTH IN OIL CONTAMINATED SOIL ACROSS FOUR LOCATIONS

\begin{tabular}{|c|c|c|c|c|}
\hline Location & & $\begin{array}{l}\text { Shoot length } \\
(\text { mean } \pm \mathrm{SE}) \mathrm{cm}\end{array}$ & $\mathrm{T}$ & P-Value \\
\hline \multirow[t]{2}{*}{ Polo } & Control & $7.9167 \pm 1.55923$ & 2.146 & 0.017 \\
\hline & Treatment & $4.208 \pm 0.78174$ & & \\
\hline \multirow{2}{*}{$\begin{array}{l}\text { Bama motor } \\
\text { park (Bama } \\
\text { road) }\end{array}$} & Control & $8.2500 \pm 1.2316$ & 4.540 & 0.04 \\
\hline & Treatment & $2.2500 \pm 0.4787$ & & \\
\hline \multirow[t]{2}{*}{ Lagos street } & Control & $7.333 \pm 1.69819$ & 1.733 & 0.02 \\
\hline & Treatment & $4.1667 \pm 0.67514$ & & \\
\hline \multirow[t]{2}{*}{ Damboa Road } & Control & $6.2500 \pm 1.69726$ & 2.993 & 0.000 \\
\hline & Treatment & $0.9167 \pm 0.54298$ & & \\
\hline
\end{tabular}

Table 2 reveals the growth differences of maize plants by shoot length in oil contaminated soil after 3 weeks of sowing. The data recorded shows that maize sown in the control has the best response across the four locations. The data in Polo, Bama motor park, Damboa road and Lagos Street reveals that there were significant differences $(\mathrm{P}<0.05)$ in the shoot length between the control and the treatment across the 4 location. Similarly, the best response in the control was recorded in Polo showing 4.208 with least recorded in Damboa road $(0.91667 \mathrm{~cm})$.

According to the mean of observation in control plot, figure 1 reveals that the site with the highest number of leaves was "polo" with mean value of 6.66667 , followed by Bama motor park with the mean value of 6.00. Similarly, in the treatment plot, the site with the highest number of leaves was Lagos Street (7.41667) while the least response was recorded in Damboa road with number of leaves recording 0.833 .

In terms of shoot length in the contaminated soil, polo site has the highest shoot length recording $4.20833 \mathrm{~cm}$ while the least response was recorded in Damboa road with mean value of $0.916667 \mathrm{~cm}$. While in the control plot the best response was recorded in Bama motor park with shoot length recording $8.25 \mathrm{~cm}$ and the least response was recorded in Damboa road with shoot length of $6.25 \mathrm{~cm}$. 


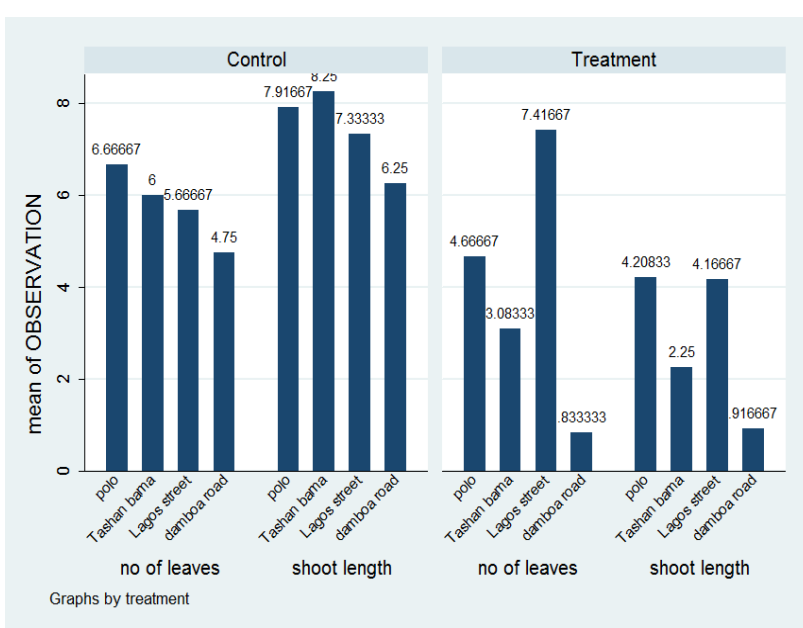

Fig.1. Growth Response of Maize in Control and Treated Soil Across Four Locations

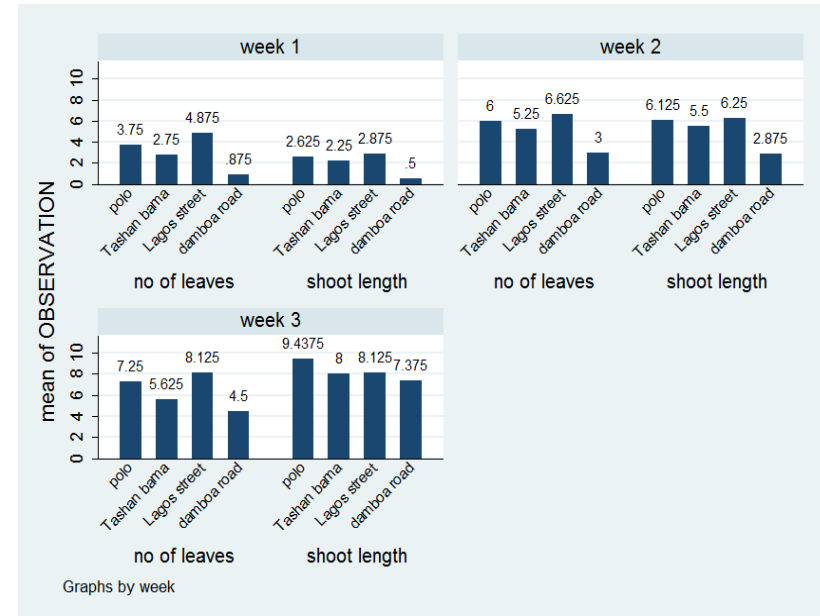

Fig. 2. Weekly Growth Response of Maize in Control and Treated Soil

Across the Four Locations.

\section{A. Isolates obtained from used engines oil contaminated soil}

Several dilution techniques were employed in isolating bacteria from samples contaminated with used engine oil. The isolates were then identified by biochemical morphological characteristics and are found positives (degraders of engine oil) by oil spread method. In totality, different species of bacteria were isolated. The probable bacteria isolated were pseudomonas spp, streptococcus spp and bacillus spp.

\section{B. Morphological and biochemical characteristics of isolates}

The pseudomonas spp. which was isolated produced colonies [8] which were small round slightly raised and produced blue green water-soluble pigments [1]. The bacteria were oxidized positive, oxidized glucose in the oxidation formation test and were indole negative. They were also non spore forming, gram negative, and catalyst positive motile and aerobic rods. Morphologically, streptococcus was found non motile, non-spore forming catalyst negative cocci that occur in chains, gram positive and bacillus spp which were isolated produced cream, circular, entire, opaque, flat and rough edges. Microscopically bacillus spp were seen as gram positive long rods with a central spore.

This project research was done to see the effectiveness of bioremediation and to know which site can support plant growth at different exposure rate of used engine oil. The result obtained from this research, bioremediation was more effective in two locations, Lagos Street and Polo because of the less exposure rate compared to the other two locations Bama road and Damboa road.

There was a different finding on the effects of hydro carbons in the environment, according to [9] in motor mechanic workshops there has been a constant change in the soil microorganism as a deliberate spillage of used engine oil. This alters the biomass and ecology of soil such that both microorganisms and grasses can no longer grow on the soil spots. The colour and texture of the soil are affected; this lists the different microbial flora establishment in an attempt to remedy the petroleum product spillage.

Reference [7], reported that nutrient availability is dependent on the nature of the environment sometimes and that nutrients like nitrogen and phosphorus could be limiting sometimes and thus affecting the bio degradation process. Also, the presence of high numbers of hydrocarbon degraders has been linked to high level of nutrients made available [7].

From this finding the organisms isolated were Psedomonas aeruginosa, Micrococus sp., Bacillus sp. and Serratia $s p$. And thus, this result correlates with this research.

\section{Conclusion AND Recommendation}

The results obtained from this project research showed that all organisms isolated from the contaminated soil can be used for bioremediation process. The organisms' isolated (Pseudomonas, Streptococcus and Bacillus species) were very effective in bioremediation of soil contaminated with used engine oil. Government should engineer the strains (produce genetically modified species) in large amount and give more emphasis in remediating mechanic workshops, especially the sites that have been in existence for more than ten years like Bama motor park and Damboa road locations.

Bioremediation can be regarded as the best option which is safe, robust and economical technology for soil to become a harmless agricultural platform i.e fertile in order to support plant growth. Hence, further research needs to be carried out to develop different strains that would be more efficient in the utilization of different fractions of petroleum hydrocarbons.

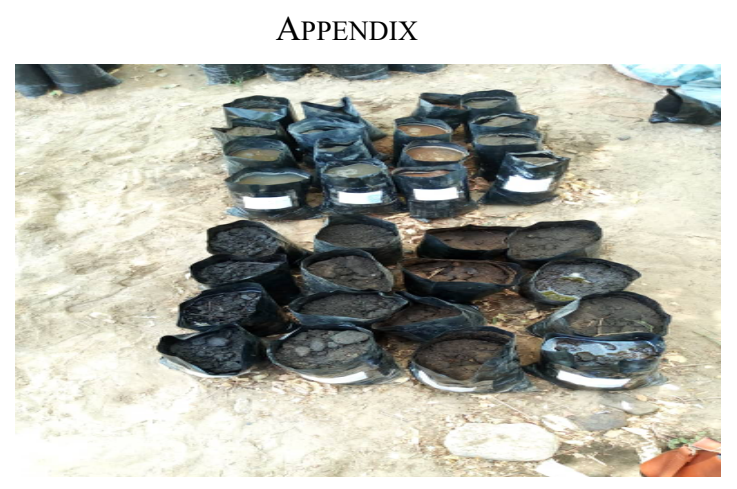




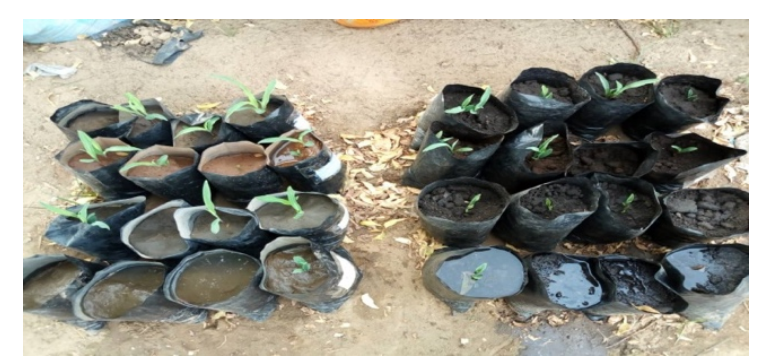

Appendix 1: Shows Growth of Maize in Control and Contaminated Plot in Week 1
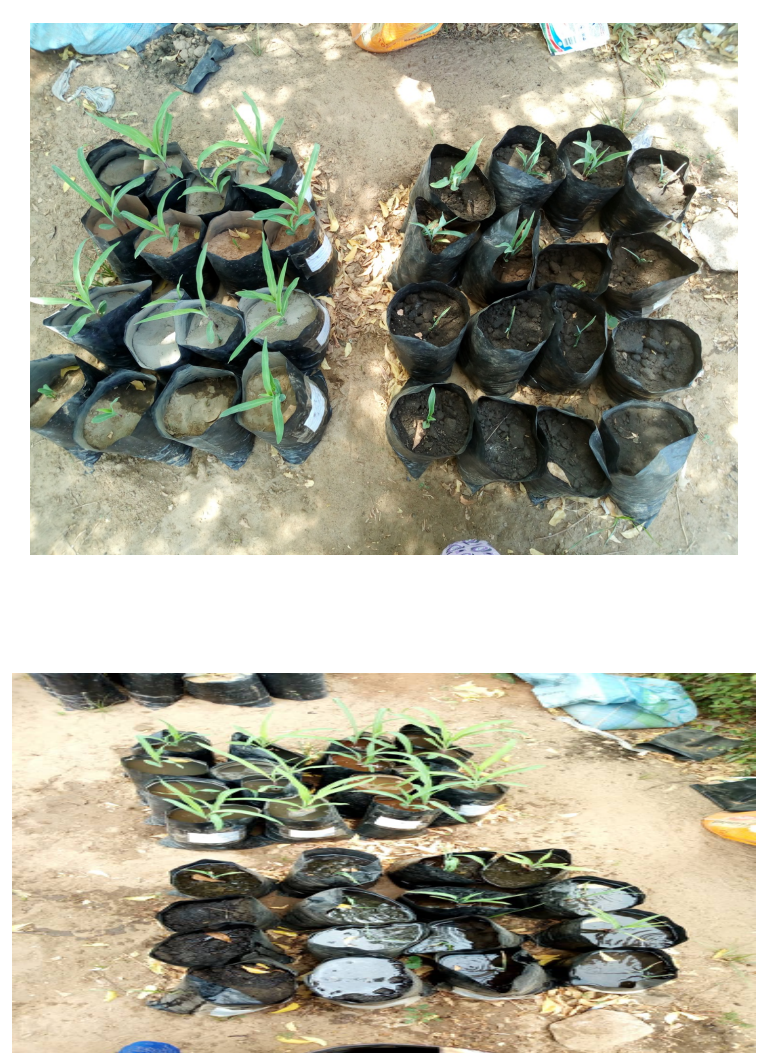

Appendix 2: Shows Maize Growth In Week 2 to 3

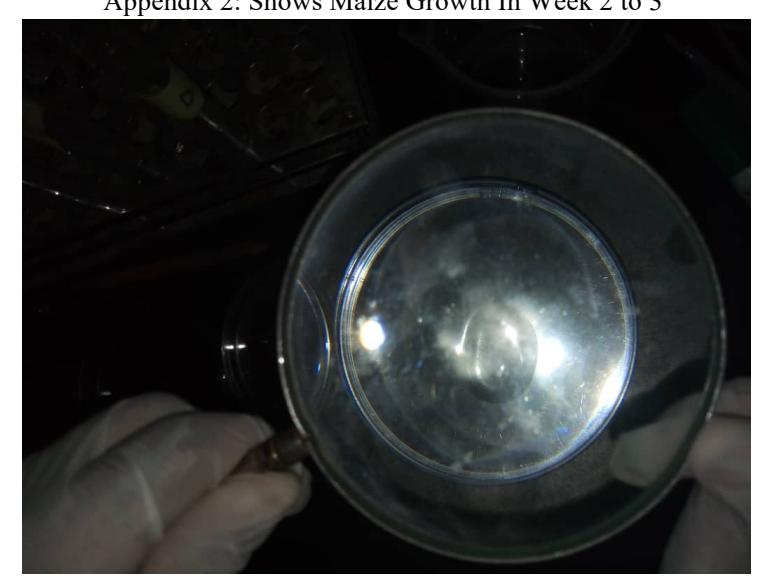

Appendix 3: Shows Aggregation of Distilled water, Crude oil and microorganism suspension under Magnifying Lens

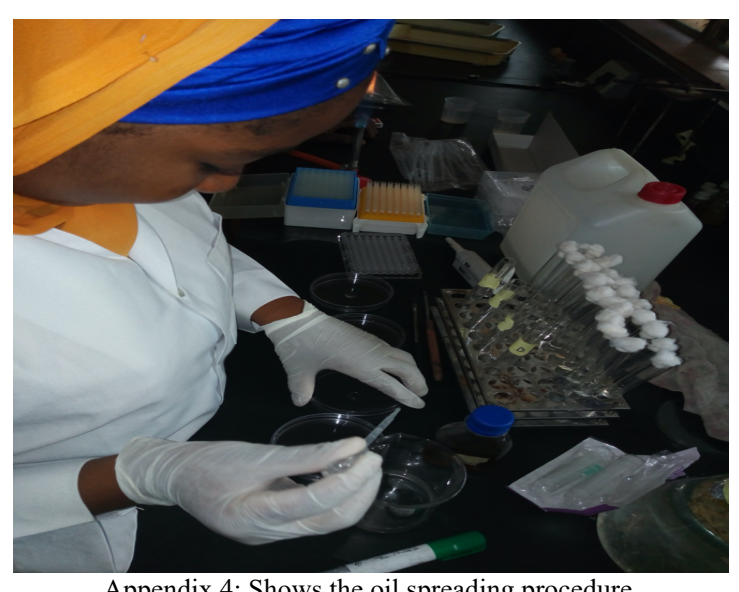

Appendix 4: Shows the oil spreading procedure

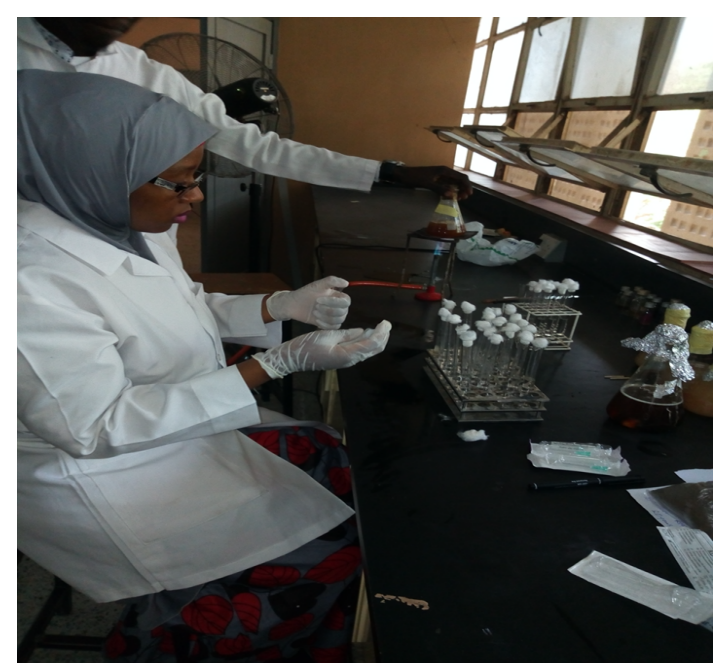

Appendix 5: Shows the Serial Dilution Procedure

\section{ACKNOWLEDGMENT}

We are grateful to University of Maiduguri and the Department of Microbiology for the Laboratory space, facility and chemicals provided during this research. This acknowledgement cannot be complete without saying a word of appreciation to the technical staff in the laboratories of the department.

\section{REFERENCES}

[1] A. M. Mukred, A. A. Hamid, A Hamzah \& W. M. W. Yusoff, Development of Three Bacteria Consortium for the Bioremediation of crude petroleum- oil in contaminated water, online journal of Biological science, 8 (4) (2008)73ISSN 1608-4217.

[2] A. M. Spormann \& F. Widdel, Metabolism of alkylbenzenes, alkanes, and other hydrocarbons in anaerobicbacteria., Biodegradation, “(2000)" 85 . http://home.eng.iastate.edu/-tge/ce421-521/brubaker.pdf. $\underline{2019}$

[3] A. A. Shahida, S. Sambo, and I. A. Salau, (2015) Biodegradation of used engine oil by fungi isolated from mechanic workshop soil in sokoto metropolis, Nigeria, sky journal of soil Science and Environmental Management

[4] A. Tinsey, T. Farewell, (2015) Soil degradation.A growing concern. Dissecting soil: Safeguarding an invaluable Natural Resource. The Environmentalist. IEMA, UK, pp.14-17

[5] C. Chris, (2007) "Implementing Phytoremediation of Petroleum Hydrocarbons, Methods in Biotechnology 23:99-108'. Humana press. ISBN1588295419

[6] P. K. Jain, V. K. Gupta, R. K. Guar, M. Lowry, D. P. Jaroli, and U.K. Chauhan, (2009) Bioremediation of petroleum oil contaminated soil and water. Research journal of environmental Toxicology, 5(1):1-26.

[7] R. M. Atlas, (1995), Pathway of Hydrocarbon in Petroleum Microbiology. Macmillian Publishing Company New York; 1-15. 
[8] S. Abdusalam, S. S. Adefila, I. M. Bugaje and S. Ibrahim (2012) Bioremediation of Soil Contaminanted With Used Motor Oil in a Closed System. Journal of Bioremediation and Biodegradation. Bioremediation Biodeg.4:172.

[9] S. J. Megharaj, I. Singleton, N. C. Mc Clure, and R. Naidu (2000). Influence of Petrolium Hydrocarbon contamination on Micro Algae and Microbial Activities in a Long-Term Contaminated Soil. Archives on Environmental Contamination and toxicology, 38:439-445.

[10] T. Mandri, J. Lin, (2007) Isolation and characterization of Engine oil Degrading indigenous Microorganisms in Kwazulu Natal, South Africa. African journal of Biotechnology, 6(1); 023-027.

[11] V. J. Odjegba and A. O. Sadiq (2002). Effect of spent engine oil on the ground parameters, chlorophyll and protein levels of Amaranthushybridus The Environmentalist, 22; 23-28.

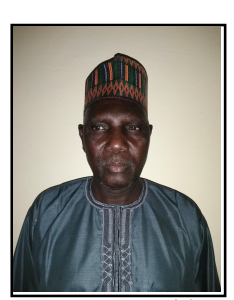

Ibrahim Yerima was born in Biu Borno State Nigeria on the $26^{\text {th }}$ of August 1959.

1. Bakin Kasuwa Primary School Biu Borno State Nigeria, 1966-1972 Primary Leaving Certificate.

2. Government Secondary School Waka Biu Borno State Nigeria, 1973-1977 West African School Certificate (WAEC).

3. B.Sc. Botany (Hons) University of Maiduguri, Borno State Nigeria, 1978-1982.

4. Post Graduate Diploma in Biological Technics; NIST Ibadan, Nigeria (1991-1992)

5. M.Sc. Land Resources (Development) Bayero University' Kano, Nigeria 1994-1999

6. Ph.D. (in View) in Geography, Department of Geography, University of Maiduguri, Borno State, Nigeria 2012-Date.

Major field of Study include Resources in Genetics, Biofuel Resources and General Plant Resources.

$\mathrm{He}$ is a lecturer in the Department of Biological Science, University of Maiduguri, Nigeria from 1983-date. He was a Chief Technologist in 2009 until his present appointment as a Lecturer in Biological Sciences. He has 17 publications in Environment and relevant fields. He was previously into Genetics research and now very active in Renewable Energy and Model Village Studies.

Mr. Yerima is an Academic Editor of Asian Journal of Advanced Research and Report effective from 09/03/2019 to 08/03/2023.

Grace Atinuke Felix was born in Maiduguri on the $18^{\text {th }}$ may 1993. B.Sc. Microbiology University of Maiduguri 2013. M.Sc. Industrial Microbiology 2018. Assistant Lecturer Department of Microbiology Unimaid.

Munirah Ibrahim Ahmad was born in Saudi Arabia in July 1996. Elkanemi Primary School 2000, Mairi Islamic Secondary School 2014. B.Sc. (Hons) Microbiology University of Maiduguri 2019. 